THE RAPID DETERMINATION OF LEAD IN ORES BY ELECTROLYSIS WITH STATIONARY ELECTRODES.

By R. C. BENNER.

Received May 9, 1910.

The determination of lead by electrolysis, when weighed as the peroxide, has, in the past, been uncertain. Nearly all investigators have found the use of a different factor necessary, but in no case has the use of the theoretical been allowable.

When the peroxide is deposited on a dish it is possible to ignite and weigh as the monoxide with excellent results, ${ }^{1}$ but with the gauze electrode it is impossible to make the ignition over the Bunsen flame in a satisfactory manner. Sand ${ }^{2}$ has been able to deposit the peroxide in such a condition that the error caused by the use of the theoretical factor when working with small amounts of lead is negligible. This was accomplished by depositing from a solution free from ammonium nitrate and the oxides of nitrogen, at a temperature of from $94^{\circ}$ to $97^{\circ} \mathrm{C}$, , using a current of five amperes. When the deposition was performed under these conditions he used the factor $0.865 \mathrm{I}$ after drying the deposit with alcohol and ether.

Recently, in the western part of the United States, the electrolytic method has been used to a great extent for the determination of lead in ores; therefore, a rapid means of carrying out this determination is of interest.

A lead nitrate solution containing 0.2508 gram of lead in Io cc. was prepared, in order that the gauze electrode $^{3}$ might be experimented with. The following determinations were made in $75 \mathrm{cc}$. of solution, in the presence of $103 \mathrm{cc}$. of nitric acid (sp. gr. 1.40) with a current of 4.8 amperes and 2.5 volts. The electrolyte was warmed during the deposition, so that the temperature of the cell was kept just below the boiling point, e. g., the highest temperature at which it is possible to carry on the electrolysis without the liberation of the oxides of nitrogen, which, according to Sand, ${ }^{3}$ tends to make the deposit non-adherent. The results below verify those obtained by Sand and give an idea of the accuracy of the method:

$\mathrm{PbO}_{2}$
found.
0.2889
0.2905
0.2903
0.5814
0.5797
0.8734
0.8715

Equivalent to $\mathrm{Pb}$.
Factor 0.886 .
0.2502
0.2516
0.2513
0.5035
0.5020
0.7564
0.7547

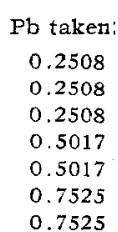

Time
13
20
20
20
25
25
25

The rate of precipitation was determined with a current of 3.5 volts and 4.2 amperes at a temperature between 94 and $97^{\circ} \mathrm{C}$. The solution in each

1. Treadwell, "Analytical Chemistry," New York, 1904, Vol. II, p. 140.

2 Chem. News, 100, 269.

3 This Journal, 2,195 case contained 0.5018 gram of lead and ro cc. of concentrated nitric acid and had a volume of $75 \mathrm{cc}$.:

$\begin{array}{cccc}\text { Rate of Precipitation. } \\ \text { Time. } & \begin{array}{c}\text { Lead } \\ \text { taken. }\end{array} & \begin{array}{c}\text { Lead deposited. } \\ \text { Factor } 0.886 .\end{array} & \begin{array}{c}\text { Peroxide } \\ \text { deposited. }\end{array} \\ \text { Min. } & 0.5008 & 0.2412 & 0.2789 \\ 1 & 0.5008 & 0.4126 & 0.4766 \\ 2 & 0.5008 & 0.4536 & 0.5237 \\ \mathbf{3} & 0.5008 & 0.4871 & 0.5623 \\ \mathbf{4} 1 / 8 & 0.5008 & 0.5012 & 0.5787 \\ \mathbf{5} & 0.5008 & 0.5007 & 0.5782\end{array}$

These results show that it is possible to deposit all of the lead, which can occur in a 0.5000 gram sample of ore, in from 5 to Io minutes. In this case, as with copper, by far the greater part of the lead was deposited in the first few minutes. 90 per cent. was deposited in the first 3 minutes, while the remaining ro per cent. took 3 minutes longer.

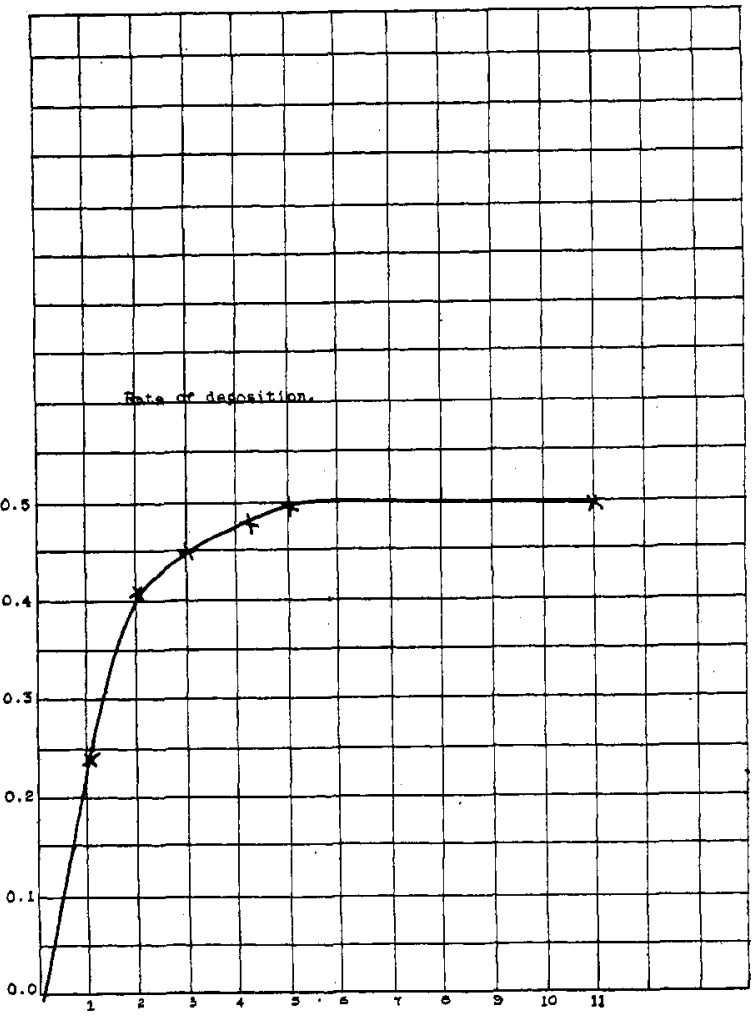

It was possible to remove all of the sulphur from galena as well as from some other sulphides, in form of hydrogen sulphide, by warming with hydrochloric acid ( 2 to I). This made it possible to use the following process for those ores which contain no interfering sulphides. From 0.5 to $I . O$ gram of the finely pulverized ore was weighed out, warmed with $x_{5}$ to $20 \mathrm{cc}$, of hydrochloric acid (2 to I) until completely disintegrated and all of the sulphur evolved as hydrogen sulphide, but not concentrated so far that the lead chloride crystallized out (this caused violent bumping). Then $20 \mathrm{cc}$. of concentrated nitric acid were added and boiling continued until all of the hydrochloric acid was expelled and the nitric 
acid had a volume of ro $\mathrm{cc}$. It was then diluted to $75 \mathrm{cc}$. and electrolyzed in the usual manner. Those ores containing sulphides, which rendered the use of the preceding method impossible, were disintegrated with nitric and hydrochloric acids, i $5 \mathrm{cc}$. of sulphuric acid added and the solution evaporated until heavy white fumes of sulphuric anhydride were evolved. After cooling, 5o cc. of water were added; it was boiled until all of the basic iron sulphate was dissolved, then the solution was diluted to $200 \mathrm{cc}$., filtered, and washed free from sulphuric acid. (As much lead sulphate as possible was left in the beaker and washed by decantation.) The lead sulphate was washed from the filter with the smallest possible amount of water into the beaker containing the bulk of the sulphate. Then ro cc. of a warm saturated solution of ammonium carbonate were poured through the filter, received in the beaker containing the lead sulphate and warmed until all of the sulphate was converted to the carbonate. The lead carbonate was then filtered through the same paper, washed with water until nearly free from ammonium carbonate, dissolved in $40 \mathrm{cc}$. of nitric acid ( 1 to 3 ), the filter paper washed free from lead and the solution electrolyzed in the usual way. The following results on a lead ore containing copper show the accuracy of the method:

Analysis of the ore by ordinary methods: Ore No. I-2.70 per cent. copper, 21.50 per cent. lead. Ore No. 2-2.28 per cent. copper, 22.20 per cent. lead.

Electrolytic determination of lead: Ore No. I2 I.52, 2 I.5 I, 2 I.59. Ore No. 2-22.20, 22.06.

Where it was desired to do away with the use of the factor and, at the same time, use the electrolytic method of determination, it was possible to do so by igniting, in a muffle, or small electric oven at a temp. of about $500^{\circ} \mathrm{C}$., the gauze electrode on which the peroxide had been deposited. The following results show the accuracy of this modification of the electrolytic method:

Lead taken.
0.2509
0.2509
0.5018
0.5018
0.7527

$$
\begin{gathered}
\text { Lead found. } \\
0.2511 \\
0.2506 \\
0.5035 \\
0.5026 \\
0.7518
\end{gathered}
$$

UNIVERSITY OF ARIzONA, TUCSON.

\section{THE VALUE OF A CHEMICAL ANALYSIS AS SHOWN IN TRACING THE CAUSE OF A TYPHOID FEVER EPIDEMIC IN GEORGIA.}

By H. B. Arbuckle.

Received June 25, 1910.

Last October a sudden and virulent outbreak of typhoid fever occurred in a college community in Georgia, four institutions being simultaneously affected.
It was thought at first that some form of food supplies, as canned goods, which were served uncooked, was responsible for the epidemic, but chemical and bacterial examinations of all the canned supplies placed them above suspicion. A competent bacteriologist went over the situation and after carefully examining the dairy products, the pantry, the sanitary arrangements and the water supply, issued a written statement to the effect that as far as his investigation went no local cause was discovered. Already twenty had contracted fever, and three to four cases were being reported daily.

At this point the author undertook an investigation in which he was ably assisted by the local physician, Dr. Mary Sweet; who furnished a comprehensive history of each case. The data showed that all the cases were located in two brick dormitories which housed about 75 per cent. of the students. These buildings were infested with ants, while the others were not, and it was thought probable that these pests were distributing the bacilli, but experiments with a large number of ants, collected in many parts of both buildings, gave no indication of pathogenic germs.

Another examination of the pantry, the dairy and its products, confirmed the first and showed very satisfactory conditions. By, this time the situation had become so serious that it was deemed wise to boil the water, milk and butter, as well as to sterilize every particle of food by thorough cooking.

The water supply, obtained from a well, was next taken up, although the bacterial examination was considered satisfactory by the local physician. The first chemical test applied to the drinking-water placed it under suspicion, as it showed high nitrites, a rough quantitative test giving one-tenth of one part per million, which is quite unusual in waters of the vicinity. Chlorides were present in unusual quantity and free ammonia was far above the amount found in a normal water of the vicinity. All of these data indicated pollution of the well water and gave a starting point for further investigation.

The well from which the drinking-water is obtained is forty feet deep, situated over fifty feet from the buildings, and on the opposite of the water-shed from the sewers. This well was cleaned twice during each year and was carefully cased with brick and cement for three feet above ground. The well and pump appeared to be in good condition.

The investigation was pushed in every direction. One hundred and fifty feet from the well supplying the drinking-water was an old well, kept as a protection against fire. The water of this well was examined and the quantities of nitrites, free ammonia and chlorides were even greater than those found in the first well, giving conclusive evidence of recent sewage pollution. Samples of water from both 